\title{
Using community-based participatory research in improving the management of hypertension in communities: A scoping review
}

\begin{tabular}{|c|c|}
\hline \multicolumn{2}{|c|}{$\begin{array}{l}\text { Authors: } \\
\text { Pugie T. Chimberengwa }{ }^{1,2} \\
\text { Mergan Naidoo }\end{array}$} \\
\hline \multicolumn{2}{|c|}{$\begin{array}{l}\text { Affiliations: } \\
{ }^{1} \text { Discipline of Public Health } \\
\text { Medicine, School of Nursing } \\
\text { and Public Health, University } \\
\text { of KwaZulu-Natal, Durban, } \\
\text { South Africa }\end{array}$} \\
\hline \multicolumn{2}{|c|}{$\begin{array}{l}{ }^{2} \text { Ministry of Health and Child } \\
\text { Care, Zimbabwe }\end{array}$} \\
\hline \multicolumn{2}{|c|}{$\begin{array}{l}{ }^{3} \text { Discipline of Family } \\
\text { Medicine, School of Nursing } \\
\text { and Public Health, University } \\
\text { of KwaZulu-Natal, Durban, } \\
\text { South Africa }\end{array}$} \\
\hline \multicolumn{2}{|c|}{$\begin{array}{l}\text { Pugie Chimberengwa, } \\
\text { drchimberengwa@gmail.com }\end{array}$} \\
\hline \multicolumn{2}{|c|}{$\begin{array}{l}\text { Dates: } \\
\text { Received: } 24 \text { July } 2019 \\
\text { Accepted: } 06 \text { Apr. } 2020 \\
\text { Published: } 16 \text { July } 2020\end{array}$} \\
\hline \multicolumn{2}{|c|}{$\begin{array}{l}\text { How to cite this article: } \\
\text { Chimberengwa PT, Naidoo M. } \\
\text { Using community-based } \\
\text { participatory research in } \\
\text { improving the management } \\
\text { of hypertension in } \\
\text { communities: A scoping } \\
\text { review. 2020;62(1), a5039. } \\
\text { https://doi.org/ 10.4102/ } \\
\text { safp.v62i1.5039 }\end{array}$} \\
\hline \multicolumn{2}{|c|}{$\begin{array}{l}\text { Copyright: } \\
\text { ( } 2020 \text {. The Authors. } \\
\text { Licensee: AOSIS. This work } \\
\text { is licensed under the } \\
\text { Creative Commons } \\
\text { Attribution License. }\end{array}$} \\
\hline \multicolumn{2}{|l|}{ Read online: } \\
\hline 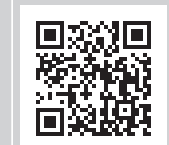 & $\begin{array}{l}\text { Scan this QR } \\
\text { code with your } \\
\text { smart phone or } \\
\text { mobile device } \\
\text { to read online. }\end{array}$ \\
\hline
\end{tabular}

Background: Hypertension (HT) is a key contributor to cardiovascular diseases (CVDs). The improved management of HT in the community and primary care settings should be a priority for low- and middle-income countries (LMICs). Improving the prevention and management of HT in primary care settings should also be a priority for developing countries. There is a need for more studies using community-based approaches that show the impact of these programmes on HT outcomes, which may motivate policymakers to invest in such approaches. The ward-based outreach team or village healthcare worker models were meant to provide such approaches, but many of these have become lower levels of curative care. We conducted a scoping review to examine how community-based participatory research (CBPR) was being used to improve HT management.

Methods: Several electronic databases were searched, namely PubMed, MEDLINE, Google Scholar and Web of Science, generating 798 references. The publications were screened through several rounds. Data were extracted and imported into a Microsoft Excel spreadsheet, numerically summarised and qualitatively analysed.

Results: Nine articles were included. These publications originated from the United States, Colombia, Canada, China, South Africa and Zimbabwe. Mixed methods, qualitative, randomised control trials and quasi-experimental studies were used to implement CBPR in the studies included. All the studies addressed complex health problems and inequities among the minorities utilising multiple stakeholder participation. Academic-community coalitions were formed, which enabled engagement and sharing of power equitably. As a result, there was acceptability and sustainability of interventions.

Conclusion: A CBPR framework can be used to define the context, group dynamics, implementation and outcomes of HT. It is possible to apply CBPR in HT management to appropriately address health disparities while emphasising a community-driven approach. To achieve this, tailored health education platforms should be developed and implemented.

Keywords: Hypertension; community-based participatory research; prevention and control; participatory action research; health and social care.

\section{Background}

Hypertension (HT) is a global public health condition and a leading cause of death and disability in developing countries. ${ }^{1}$ The prevalence of HT is highest in the African region at $46 \%$ of adults aged 25 years and above, while the lowest prevalence of $35 \%$ is found in the Americas. ${ }^{1}$ Not only is HT more prevalent in low- and middle-income countries (LMICs) as a result of weak health systems, but the number of people who are undiagnosed, untreated and uncontrolled is also high. ${ }^{1,2}$ Hypertension rarely causes symptoms in the early stages and many people go undiagnosed. ${ }^{2}$ Those who are diagnosed may lack access to care and treatment and may fail to control their illness over the long-term.

Higher incidence rates for HT are attributed to aging, unhealthy food intake, living a sedentary lifestyle, smoking, excessive alcohol intake, physical inactivity and chronic stress. ${ }^{3}$ The poor management of chronic diseases at primary care level results in a huge burden in treating complications at secondary care and results in high morbidity, premature death and subsequent premature loss of human capital. ${ }^{4}$ Improving the management of chronic diseases in primary care settings should be a priority for LMICs. ${ }^{5}$ The predominant medical model for intervention 
in the management of HT adopts a top-down approach where policies and management decisions are made at the macro level to be implemented at the micro level. ${ }^{6}$

There is a need for more studies using community-based approaches that show the impact of these programmes on HT outcomes, which may motivate policymakers to invest in such approaches. The ward-based outreach team or village healthcare worker models were meant to provide such approaches, but many of these have become lower levels of curative care. ${ }^{7,8}$ It is proposed that the most cost-effective and sustainable strategy is community-based participatory research (CBPR) ${ }^{7,8}$ A community is defined as a unit of identity, solution and practice. ${ }^{9,10}$ A CBPR is a relatively new approach and several terms such as 'participatory action research', 'participatory research' or 'action research' have been loosely and interchangeably used in literature. Community-based participatory research is a viable approach to collaborative research and improving community health. ${ }^{10,11}$ The CBPR framework emphasises equal partnership of expertise and decision-making, and ownership of the research between the community and the academic researchers. Furthermore, it appropriately addresses health disparities while emphasising a community-driven approach. It also supports capacity building, and the implementation and dissemination of research, and facilitates the sustainability of programmes in the community. ${ }^{7,12}$

The health outcomes for the management of HT are both subjective and objective in that there are many truths, hence the adoption of a mixed methods approach. To understand HT outcomes, one needs to delve into the subjective and contextual issues in the community and appreciate the importance of evidence-based medicine. The CBPR approach seeks to address these challenges as compared to a purely biomedical approach. ${ }^{8,11,12}$ Therefore, the interactive CBPR model $^{13}$ outlines at a system level capacities that are developed, policies and practices that are improved and sustained interventions that were used. It takes into consideration the context of where the research is being done, group dynamics, equitable partnerships that can be formed, the intervention and the outcomes. ${ }^{12}$ The outcomes reflect on system and capacity changes with regards to policies or practices, sustained interventions, changes in power relations and cultural renewal. ${ }^{12,13}$ These will have an effect on improved health by reducing disparities while social justice is achieved.

There is a small but increasing body of literature that describes the use of CBPR in the prevention and control of HT. However, the uses of the CBPR approach in HT care seeks to understand the experiences of communities, including those patients living with HT. The standard HT prevention practices that are in place have shown limitations as the burden of HT is increasing. The increase in HT prevalence may signify that there are problems in both primary and secondary prevention strategies which have been in use thus far. ${ }^{6}$ We undertook a scoping review of existing literature on how CBPR has been applied in communities to improve HT management. The intention was to improve our knowledge base for the wider CBPR project on HT in a rural, disadvantaged community.

\section{Methods}

Scoping studies are an increasingly popular approach to reviewing evidence in health research. ${ }^{14,15}$ Researchers may conduct scoping reviews instead of systematic reviews where the purpose of the review is to identify knowledge gaps, scope a body of literature, clarify concepts or investigate research conduct. ${ }^{16}$ Typically, these reviews provide a descriptive narrative that represent a synthesis of primary evidence available. The scoping study was part of a bigger project that had ethical approval obtained jointly from the Medical Research Council of Zimbabwe and the Biomedical Research Council of the University of KwaZulu-Natal, South Africa.

We aligned our methods to the first five of the six stages of the framework proposed by Arksey and O'Malley, and Levac et al., as shown in Figure 1. ${ }^{15,17}$

\section{Stages 1 and 2}

Our team comprised of a P.C. (principal investigator) and M.N. (supervisor), who agreed on the purpose of the study and a plan to guide the review. The specific research questions of the review were as follows: (1) What methodologies have been used in implementing CBPR to prevent HT? (2) How have partnerships developed through the CBPR approach? (3) What were the results of implementing CBPR to manage HT? (4) What gaps were identified when CBPR was used to manage HT?

\section{Criteria for including or excluding studies (stage 3)}

The inclusion criteria for this scoping review included:

- Peer-reviewed manuscripts published in journals

- Articles that have been published in the English language (due to limitations in translation capacity)

- Both quantitative and qualitative methodologies

- Studies that have mentioned CBPR in HT management

All articles searches were begun in December 2017, with the last search being done in January 2020. We included all peerreviewed publications regardless of the year of publication. There was a limit based on language, while the site was limited to the databases mentioned below.

The following electronic databases were searched: PubMed, MEDLINE, Google Scholar and Web of Science. Each database was searched for relevant titles and abstracts. Medical subject headings $(\mathrm{MeSH})$ terms included 'community based participatory research', 'hypertension action research', 'hypertension', 'community hypertension awareness', 


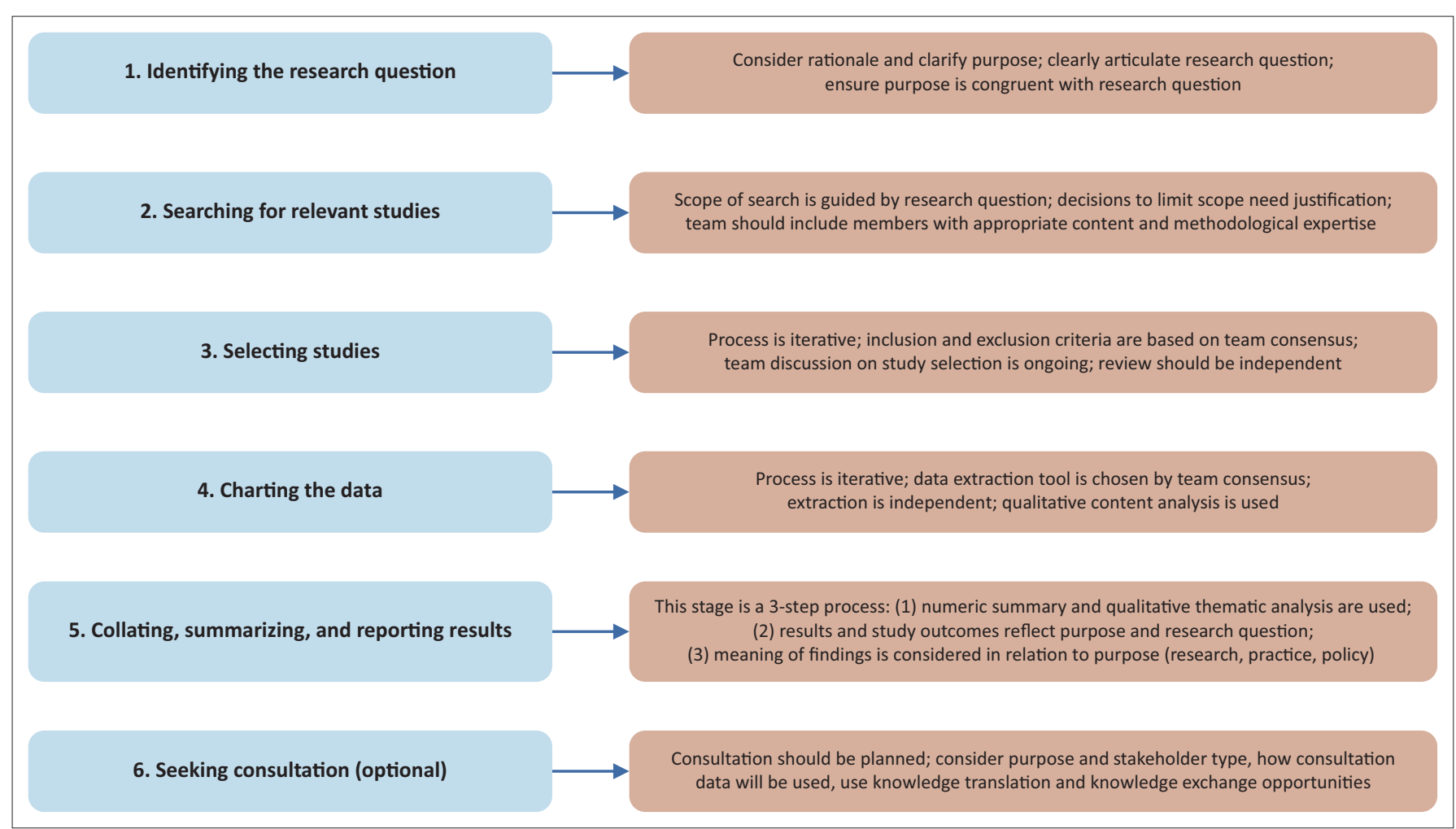

Source: Arksey H, O'Malley L. Scoping studies: Towards a methodological framework. Int J Soc Res Methodol. 2005;8(1):19-32. https://doi.org/10.1080/1364557032000119616 FIGURE 1: Scoping review stages as developed by Arksey and O'Malley.

'participatory action research', 'action research', 'community hypertension management', 'community blood pressure management' and 'hypertension implementation research'. Both authors agreed that these terms were appropriate to enable a comprehensive search for the scoping review. The search strategy shown in BOX 1 generated a total of 798 references. The reference lists of the retrieved articles were cross-referenced in order to identify additional relevant papers.

\section{Study selection, data collection and interpretation (stages 4 and 5)}

Using the pre-specified eligibility criteria, the first round of reviews created a shortlist by screening each publication's title and abstract for appropriateness. In this way, articles that were not in the scope of the review were eliminated. The shortlist was made by the P.C., and the M.N. reviewed the selection. Full articles were obtained and reviewed by the P.C. and M.N. Disagreements between authors were resolved by a discussion leading to mutual consent.

A data charting form was developed by the P.C. to consolidate a range of variables (BOX 2) through an iterative process. Data were then extracted and imported into a Microsoft Excel spreadsheet, which was summarised both numerically and by quantitative thematic analysis (stage 5). Study characteristics included socio-economic and cultural factors, university-community capacity and readiness, health issue importance; group dynamics and equitable partnerships; the type of intervention implemented during the project; and outcomes describing the desired effects, unwanted effects or side effects that arose. ${ }^{12}$
BOX 1: Search strategy for hypertension prevention and control, and community-based participatory research literature.

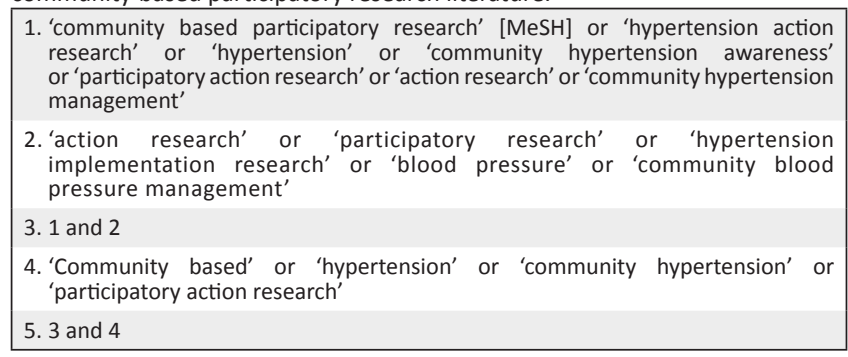

BOX 2: The variables charted from included literature on community-based participatory research in the prevention and control of hypertension.

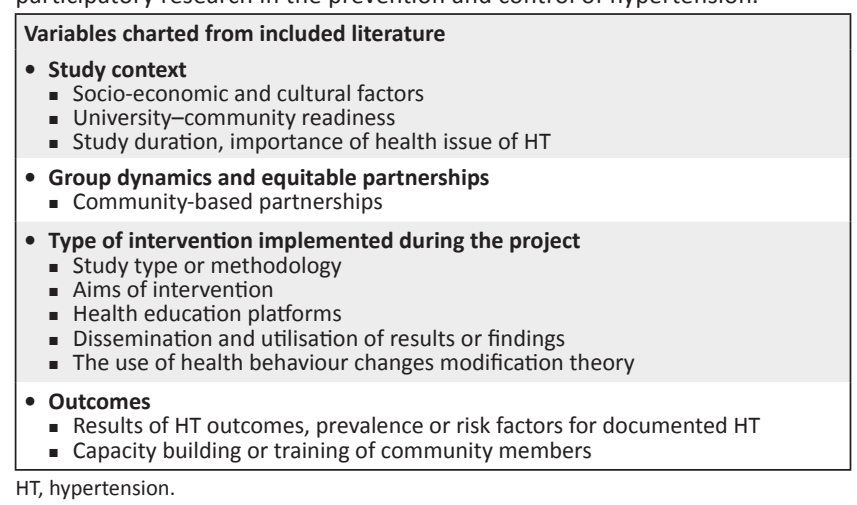

We collated numerical summaries for the type of method, study site, country of publication, duration of implementation, population description (number of participants) and duration of implementation. We also collated qualitative summaries for CBPR implementation, HT outcomes, behaviour change, 
capacity building, and the uses of evidence generated from CBPR implementation.

\section{Ethical consideration}

The scoping study was part of a bigger project that had an ethical approval obtained jointly from the Medical Research Council of Zimbabwe (MRCZ/A/2136) and the Biomedical Research Council of the University of KwaZulu-Natal, South Africa (BFC318/16).

\section{Results \\ Description of studies}

Using the eligibility criteria and a peer-review process, nine studies were ultimately included in the analysis. Figure 2 shows the outcomes of the study identification and selection process.

\section{Study characteristics}

Table 1 shows a summary of the study characteristics indicating citation, study context, group dynamics and outcomes.

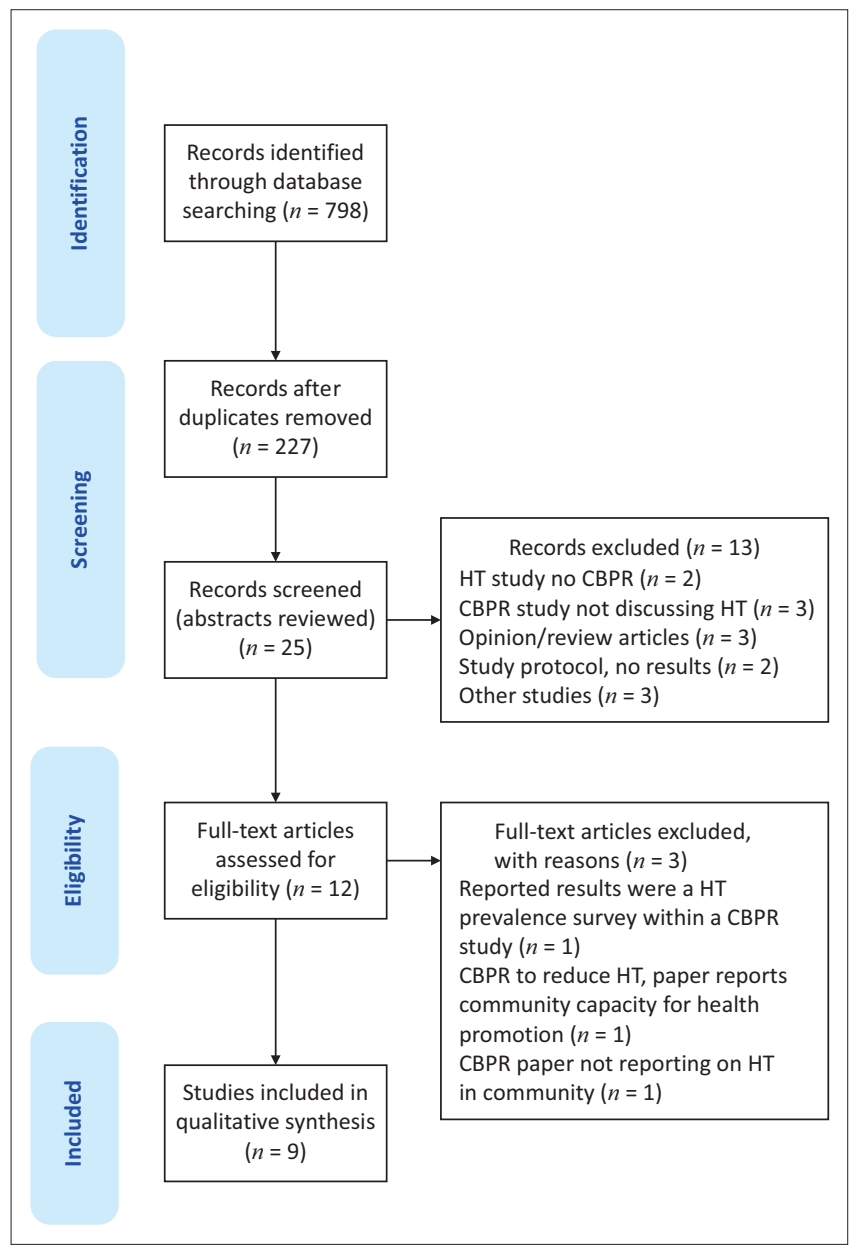

Source: Adapted from ResearchGate

CBPR, community-based participatory research; HT, hypertension; PRISMA, Preferred Reporting Items for Systematic Reviews and Meta-Analyses

FIGURE 2: PRISMA flow diagram showing records that were retrieved and screened on the use of community-based participatory research in hypertension management.

\section{Study context}

Three of the reviewed articles were written in the United States (US), ${ }^{18,19,20}$ one in Canada, ${ }^{21}$ two in Colombia, ${ }^{22,23}$ one in China, ${ }^{24}$ one in South Africa ${ }^{25}$ and one in Zimbabwe. ${ }^{26}$ Only one study had been published before the year $2010,{ }^{25}$ while the rest were published between the years 2010 and $2020.18,19,20,21,22,23,24,26$ The study setting was predominantly in an urban locale $(n=6),{ }^{18,20,21,22,23,24}$ with the other three studies having been conducted in a rural setting. ${ }^{19,25,26}$ All of the studies were conducted in poverty-stricken communities that were characterised by constrained economic opportunities, poor physical infrastructure and reduced social cohesion, all contributing to a higher prevalence of HT and ill health. In Africa, ${ }^{25,26}$ studies conducted were undertaken in black communities. In Europe, studies were on minority ethnic or racial groups which included African Americans, ${ }^{18,19}$ Hispanics ${ }^{20}$ and South Asian Canadians. ${ }^{21}$ Two studies were conducted in Colombia; the first one was on displaced marginalised communities, ${ }^{22}$ and the second was on the secondary and tertiary prevention of HT in the elderly. ${ }^{23}$

The importance of HT as a key contributor to cardiovascular diseases (CVDs) was emphasised by all the studies. ${ }^{18,19,20,21,22,23,24,25,26}$ The social determinants of the community in question were described by all of the studies $(n=9), 18,19,20,21,22,23,24,25,26$ which included socio-economic, cultural and environmental factors. All of the studies were undertaken to address health disparities among different groups of people in the community, thus the aims of the study were stated.18,19,20,21,22,23,24,25,26 The number of study participants was stated in eight of the reviewed articles; two had a total number of participants of below 20023,25; four had participants of between 200 and 50018,21,24,25; and two had participants of more than $500 . .^{19,20}$ The studies covered a wide range of HT prevention strategies - primary, ${ }^{19,22,25,26}$ secondary ${ }^{18,19,21,25,26}$ and tertiary prevention. ${ }^{14,15,16,17,19,20,21,22}$

\section{Group dynamics and equitable partnerships}

All of the reviewed articles described the formation of a coalition that included the community and the academics or researchers. ${ }^{18,19,20,21,22,23,24,25,26}$ The focus was to address complex health problems and inequities utilising multiple stakeholder participation. Various coalitions were formed and given special names; for example, 'community health research group' (CHRG), ${ }^{22}$ 'Racial and Ethnic Approaches to Community Health across the US' (REACH U.S.), ${ }^{20}$ 'Men on the Move: Growing Communities' (MOTMGC) ${ }^{19}$ and 'cooperative inquiry group' (CIG). ${ }^{26}$ Other coalitions were not given specific names. ${ }^{17,19,20,21}$ All of the partnerships included university departments or academics and community organisations, while health workers and government departments were incorporated depending on the type of study and setting. Community organisations included community-based organisations (CBOs), nongovernmental organisations (NGOs), faith-based organisations (FBOs) and the business sector. 


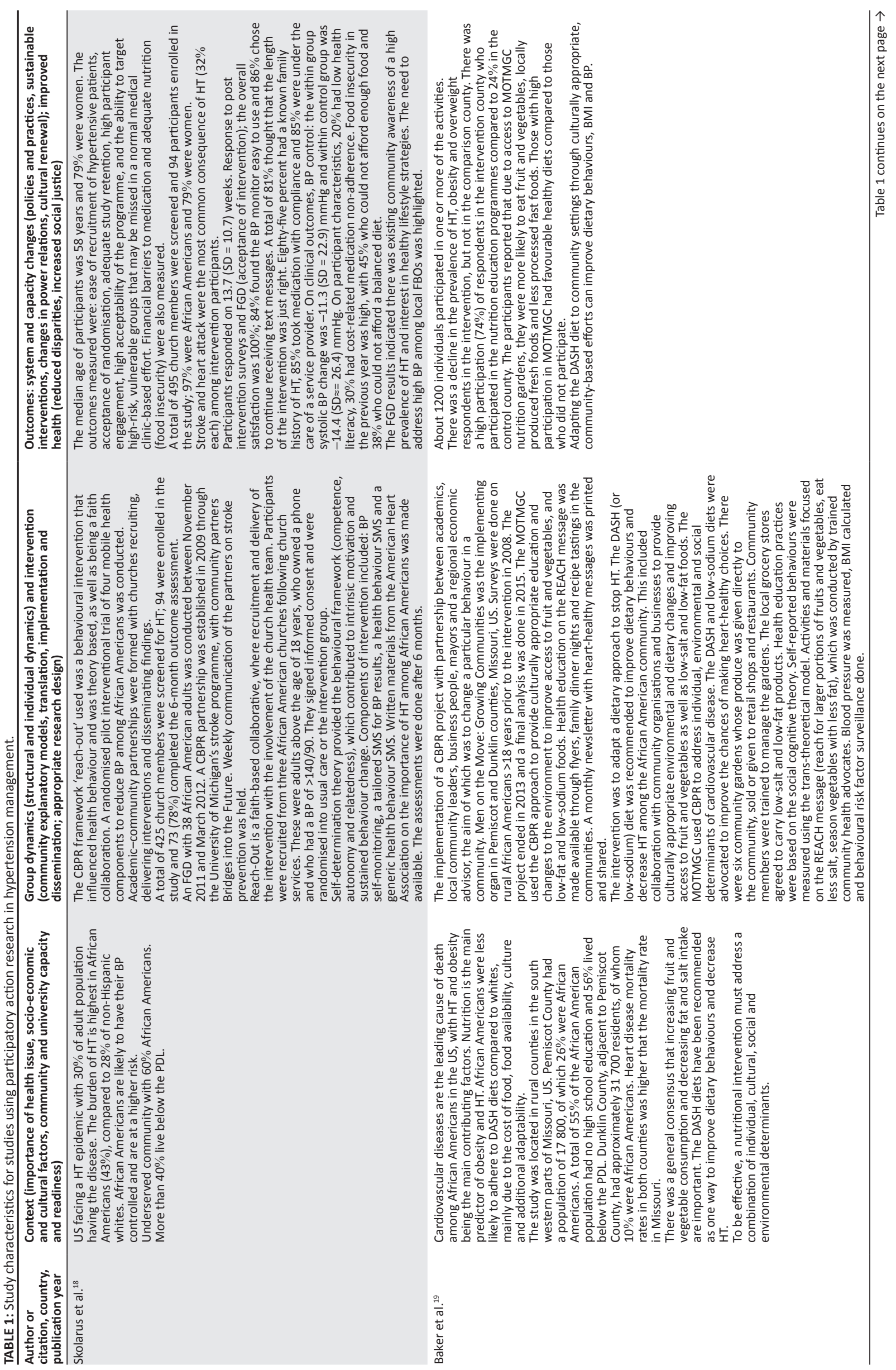




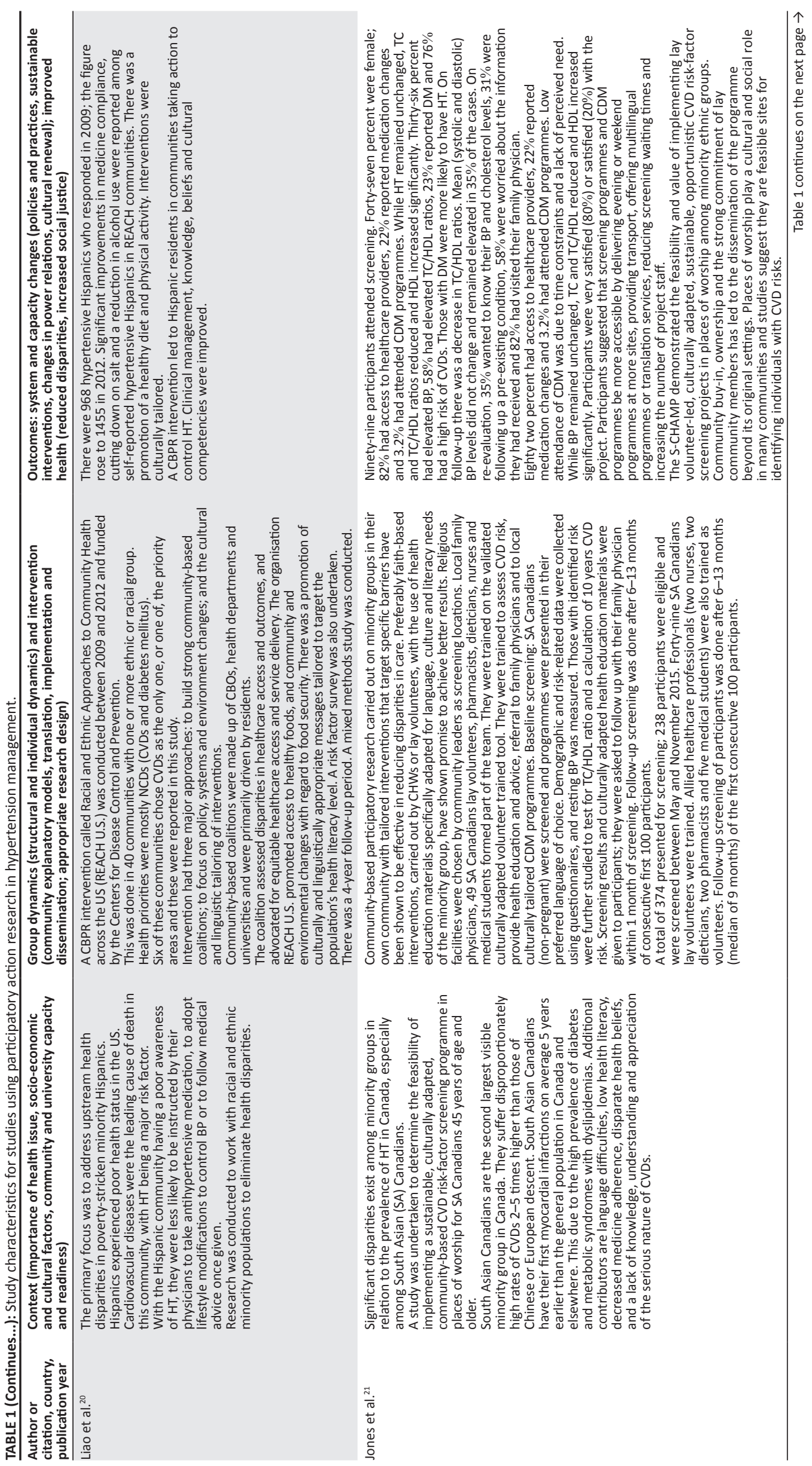




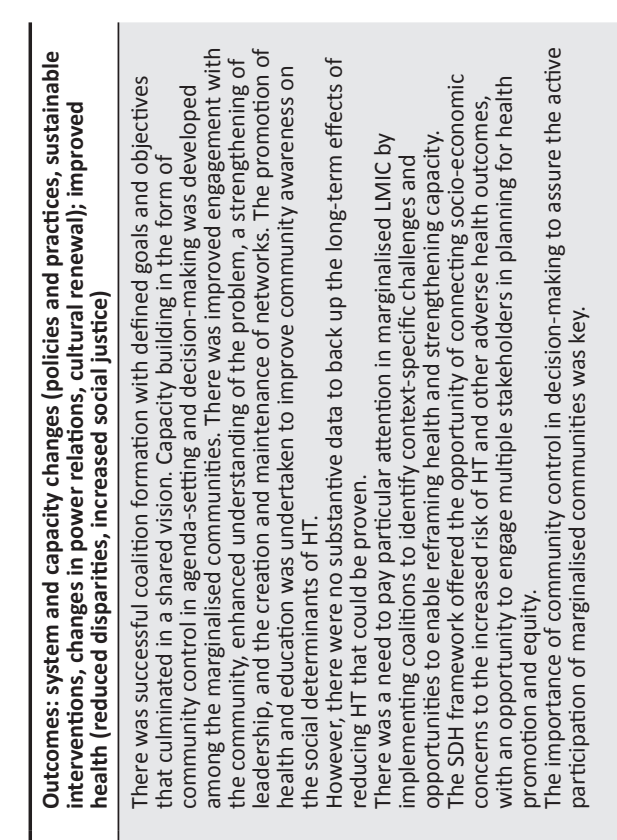

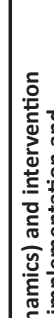

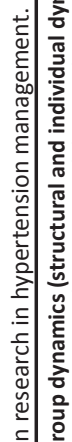

产

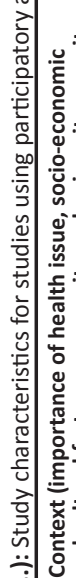

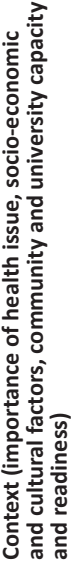

$\times \stackrel{x}{\frac{1}{6}}$

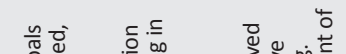

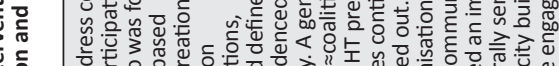

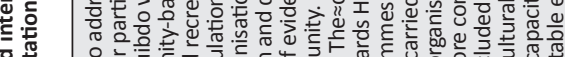

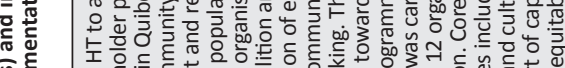

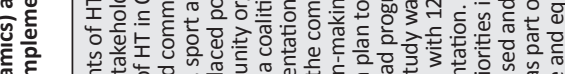

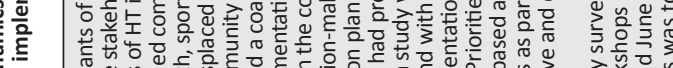

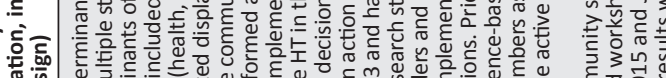

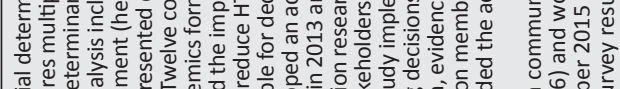

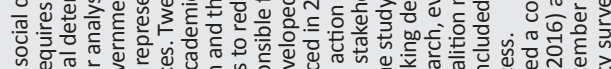

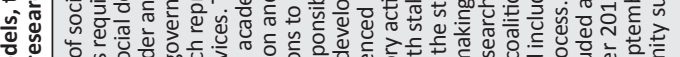

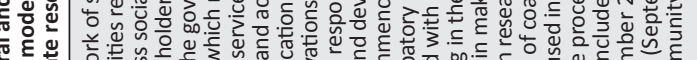

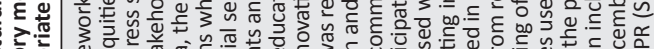

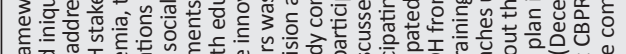

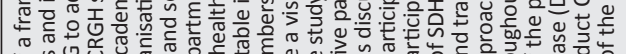

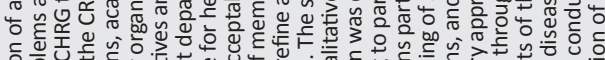

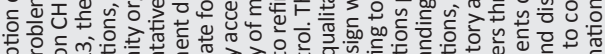

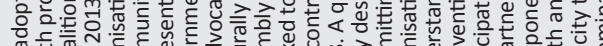

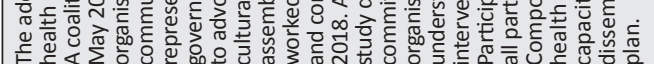

흐드

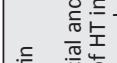

秃

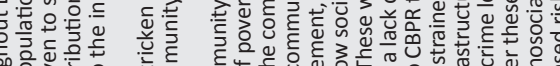

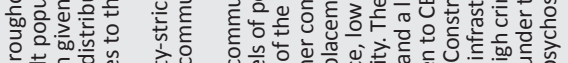

它场

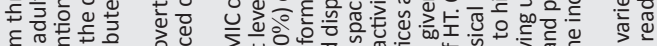

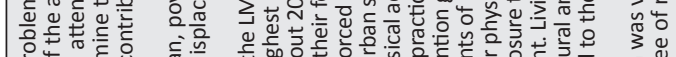

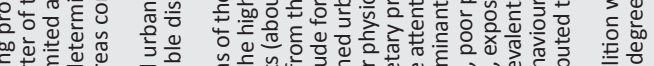

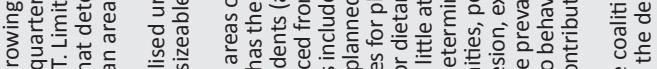

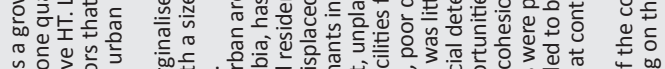

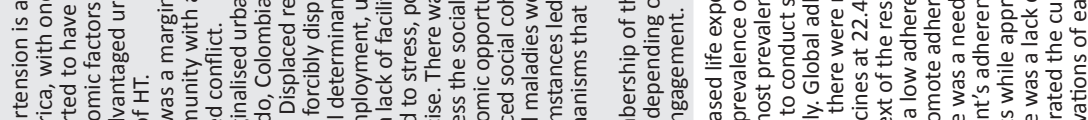

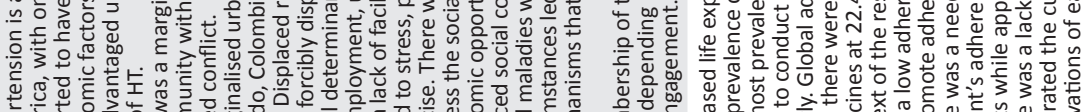

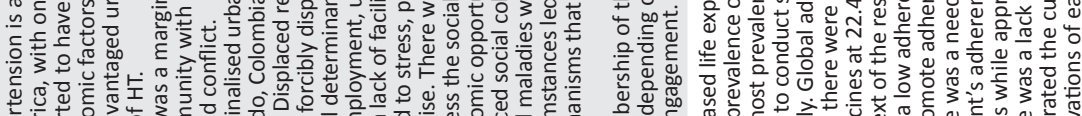

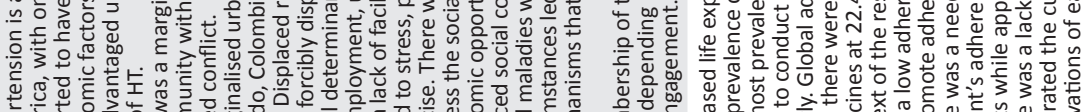

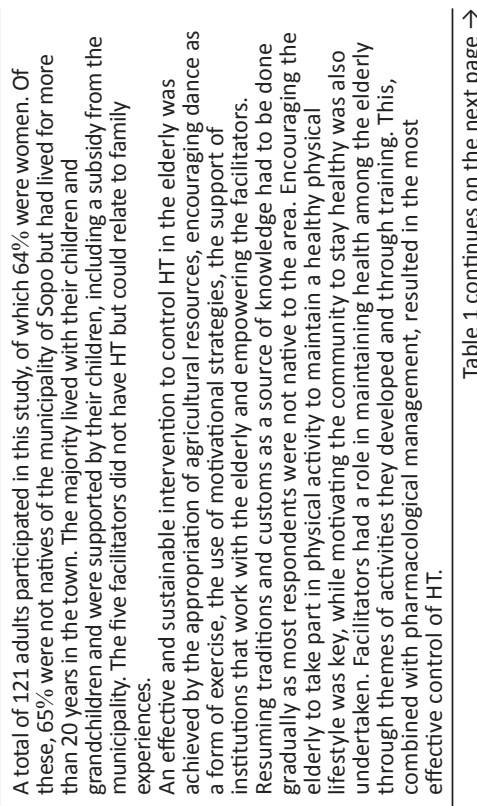

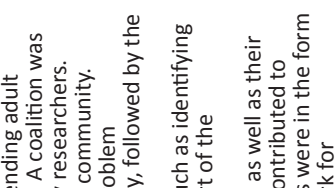

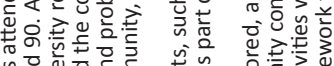

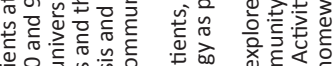

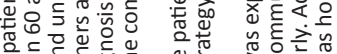

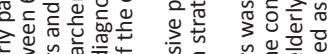

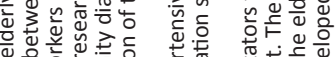

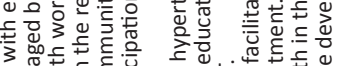

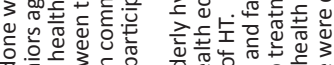

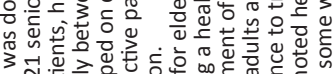

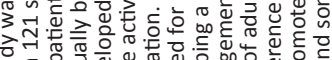

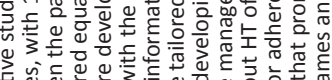

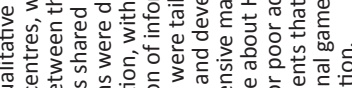

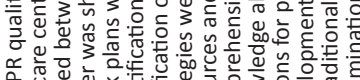

$\begin{array}{ll} & \\ 0 & \end{array}$

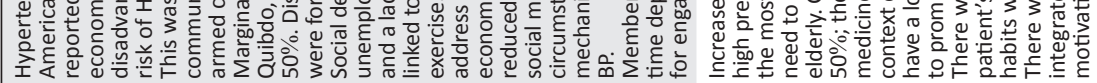

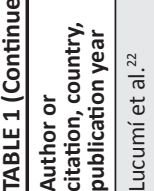

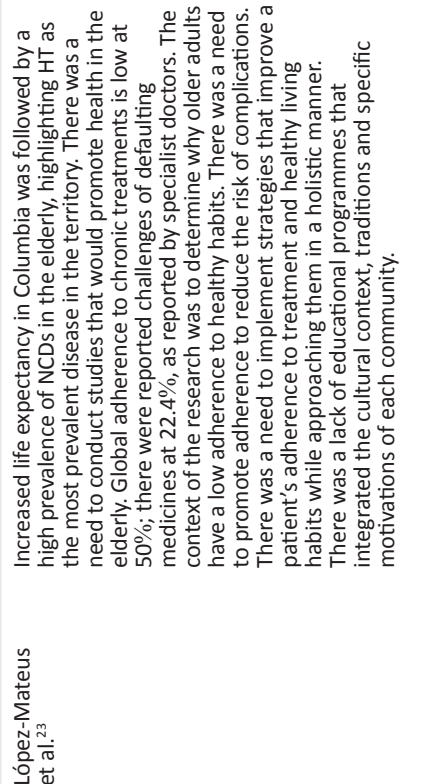




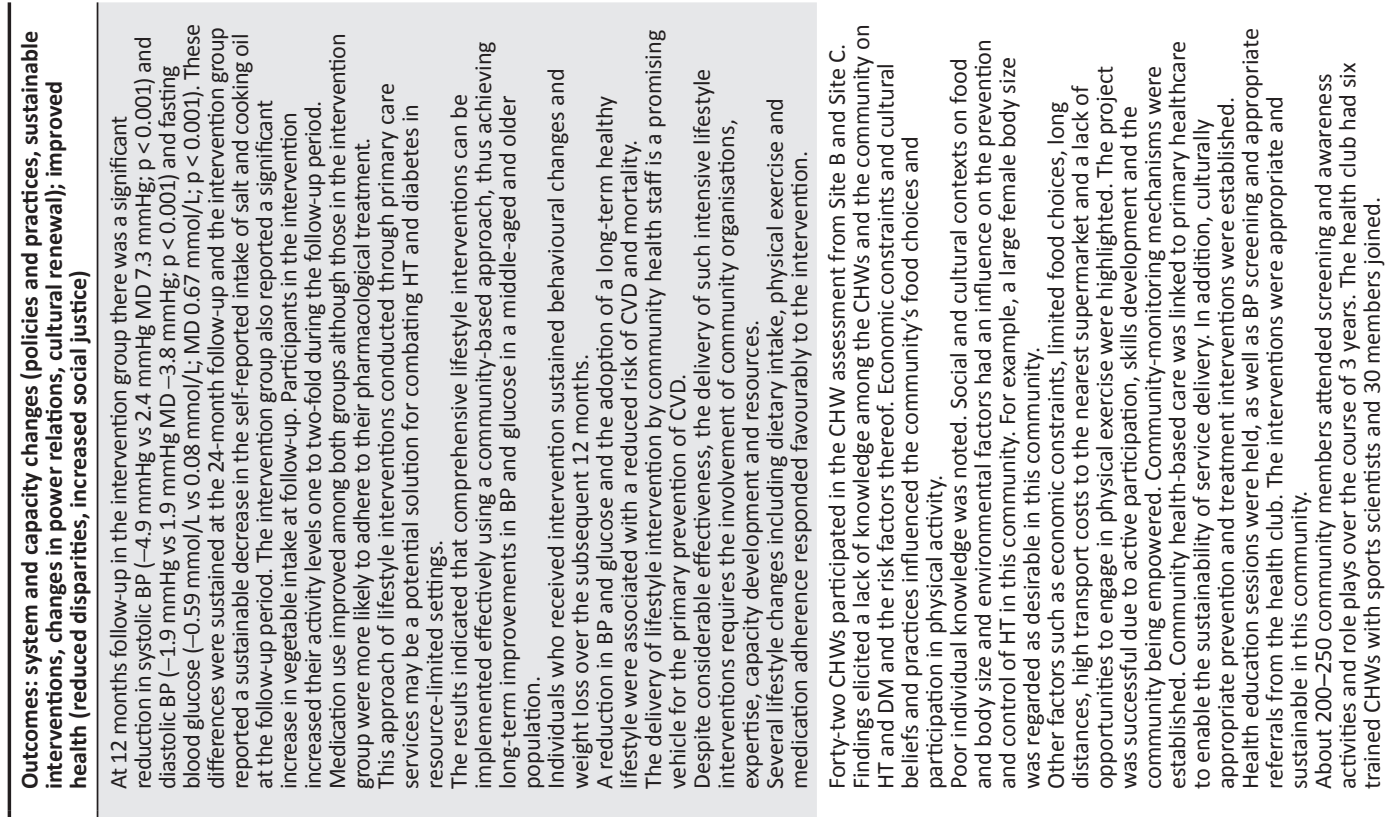

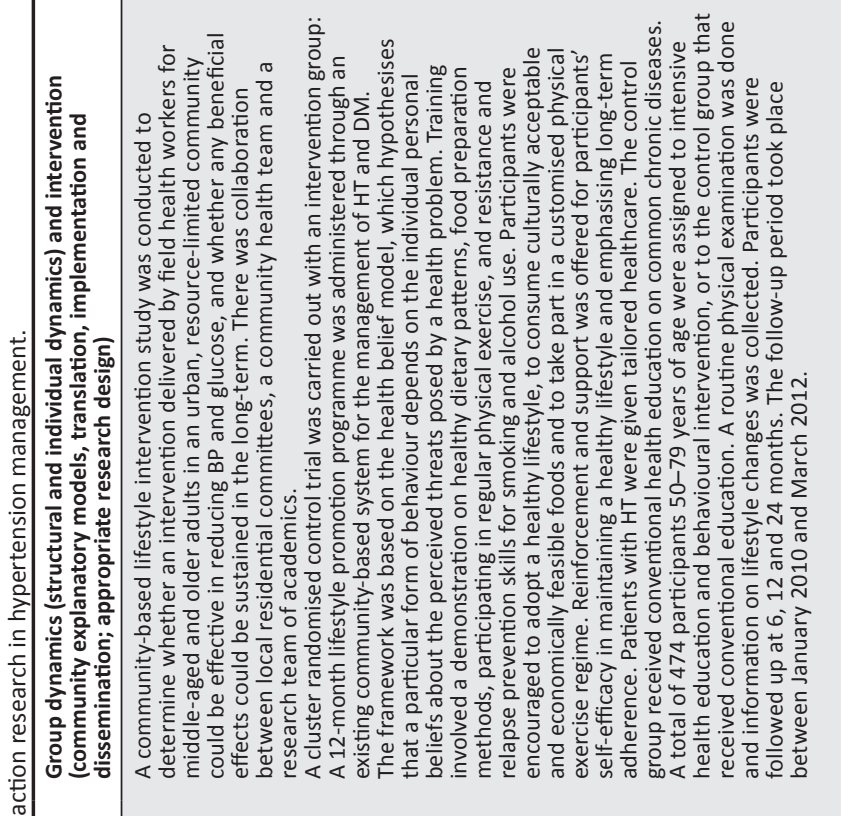

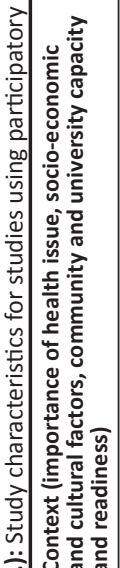

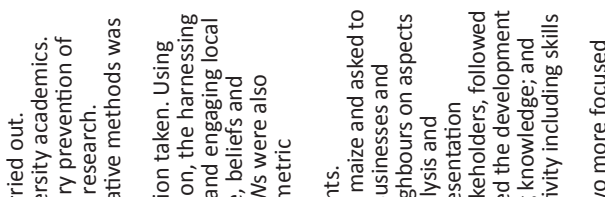

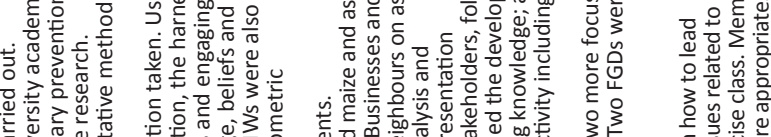

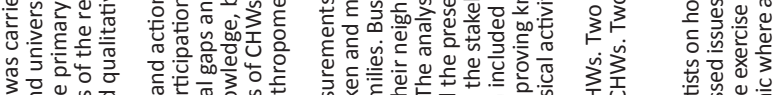

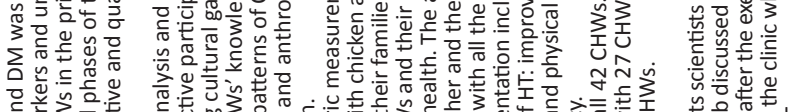

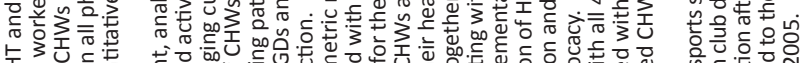

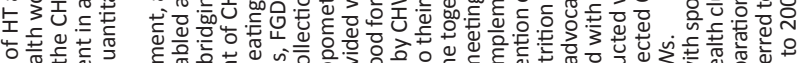
等

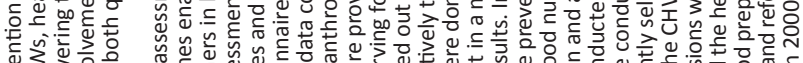

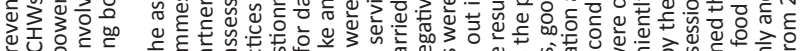

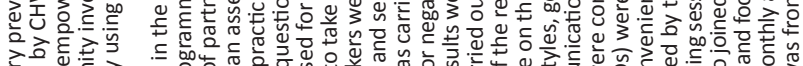

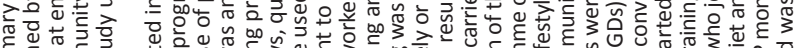

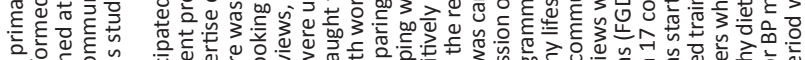
等

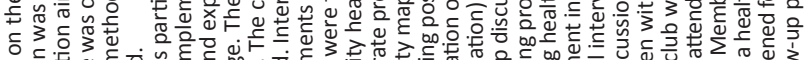

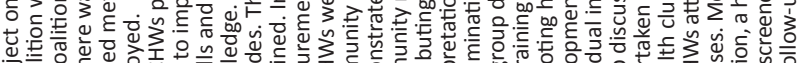

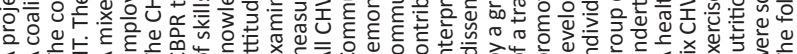

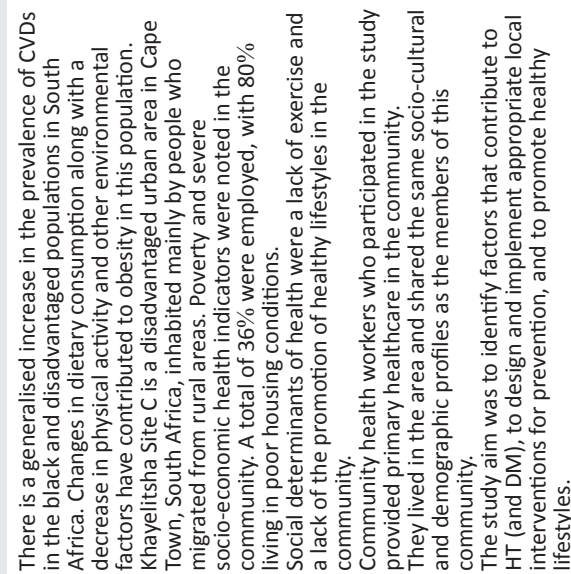




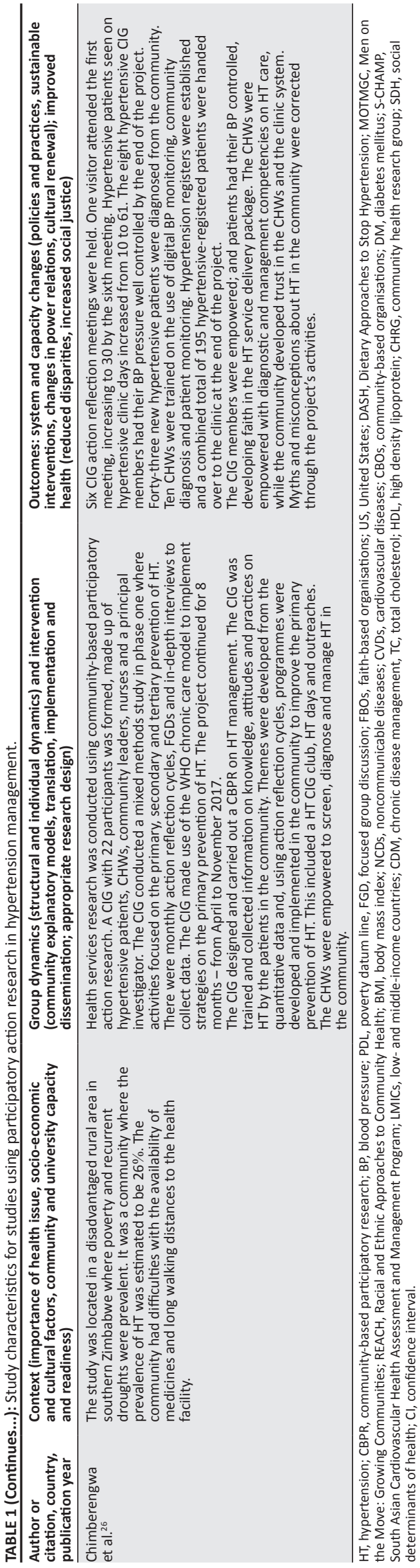

All of the studies adopted the social determinants of health (SDH) to address health disparities, ${ }^{18,19,20,21,22,23,24,25,26}$ looking at various perspectives such as displacement, ${ }^{18}$ racial and ethnic minorities, ${ }^{18,20,21}$ senior citizens in the society ${ }^{23,24}$ and other vulnerable black communities. ${ }^{15,21,22}$ There was equitable power-sharing between the academiccommunity partnerships. There was active participation in decision-making by the community members in determining the focus, implementation and dissemination of findings in all the studies. The importance of community control in decision-making ensured the active participation of marginalised communities. The use of CBPR partnerships to implement programmes enabled active participation, harnessing skills and expertise of partners in bridging cultural gaps and engaging local knowledge. $18,19,20,21,22,23,24,25$ In the process, these partnerships promoted the active and equitable engagement of all partners.

\section{Intervention}

Various methodologies were utilised in implementing CBPR, with all studies ${ }^{18,19,20,21,22,23,24,25,26}$ having reported the use of CBPR interventions in managing HT. In the implementation of CBPR, the following characteristics were described in all the studies $(n=9)$ : $(1)$ a description of research participants, (2) the ages of research participants and (3) the aims and objectives of the intervention. ${ }^{18,19,20,21,22,23,24,25,26}$ Two studies used qualitative methods, ${ }^{22,23}$ where the community research group on health $(\mathrm{CRGH})$ conducted a study on innovations on the primary and secondary prevention of $\mathrm{HT}$ in the community, ${ }^{22}$ while in the other study the coalition was working on the tertiary prevention of HT in elderly hypertensive citizens. ${ }^{23}$

Three studies reported having used mixed methods (qualitative and quantitative). ${ }^{20,25,26}$ The REACH U.S. study focused on CVDs as a priority in communities. The intervention had three major approaches: to build strong community-based coalitions; to focus on policy, systems and environment (PSE) changes; and the cultural and linguistic tailoring of interventions. ${ }^{20} \mathrm{~A}$ study on the primary prevention of HT was carried out where a coalition was formed to enable village health workers (VHWs) to actively participate in harnessing the skills and expertise of community members in order to bridge cultural gaps and engage local knowledge. ${ }^{25}$ The third study utilised a CIG to implement measures focused on the primary, secondary and tertiary prevention of HT in the community. ${ }^{26}$

Two studies were quasi-experimental CBPR interventions. ${ }^{19,21}$ The MOTMGC used CBPR to address individual, environmental and social determinants of CVD by advocating for Dietary Approaches to Stop Hypertension (DASH) and low-sodium diets, improving the possibility of people making heart-healthy choices. ${ }^{19}$ The aim was to change a 
particular behaviour in a community, with MOTMGC being the implementing organ to provide culturally appropriate education and changes to the environment to improve access to fruits and vegetables, and low-fat and low-sodium foods. The second quasi-experimental study reported CBPR carried out on minority groups with tailored interventions that targeted specific barriers; it was shown to be effective in reducing disparities in care and that making use of faithbased interventions was helpful. ${ }^{21}$ This research was carried out by community health workers (CHWs) or lay volunteers with the use of health education materials specifically adapted for the language, culture and literacy needs of the minority groups. Religious facilities chosen by community leaders were used as screening and follow-up locations.

Two studies were conducted using randomised control trials (RCTs). ${ }^{18,24}$ The CBPR framework 'reach-out' used was a behavioural intervention that influenced health behaviour and was theory based, as well as being a faith collaboration. A randomised, pilot interventional trial of four mobile health components to reduce blood pressure (BP) among African Americans. ${ }^{18}$ A cluster randomised control trial was undertaken to determine whether an intervention delivered by field health workers for middle-aged and older adults in an urban resource-limited community could be effective in reducing BP and glucose, and whether any beneficial effects could be sustained in the long-term. ${ }^{24}$ The intervention group was exposed to a 12-month lifestyle promotion programme administered through an existing community-based system for the management of HT.

The follow-up period after the implementation of CBPR was stated in all of the reviewed articles $(n=9)$, which varied from a minimum of 6 months to a maximum of 5 years. Three studies took less than a year to complete, ${ }^{18,21,26}$ one study took 2 years to complete, ${ }^{24}$ and five studies took between 4 and 5 years to complete. ${ }^{19,20,22,23,25}$ All of the articles $(n=9)$ had aims and objectives of the CBPR intervention clearly stated and $(n=8)$ of the studies $18,19,20,21,22,24,25,26$ had indicators that were being traced throughout the follow-up period. All of the studies $(n=9)$ recorded specific parameters and key events before and after the implementation process to measure changes that were attributable to the intervention. The dissemination and utilisation of the findings were reportedly done by the community members in the coalition. . $^{2,22,23,25,26}$

All of the studies had a primary objective of influencing human behaviour. To hypothesise changes in human behaviour, three studies provided a behavioural framework: the self-determination theory, ${ }^{18}$ the trans-theoretical mode ${ }^{19}$ and the health belief model (HBM). ${ }^{24}$ The rest of the studies, ${ }^{20,21,22,23,25,26}$ although they did not state the theory or model that determines changes in human behaviour, hypothesise that the social determinants in the community affect human behaviour. To achieve a change in behaviour while implementing CBPR, various health education platforms were created and reported in all of the studies. ${ }^{18,19,20,21,22,23,24,25,26}$ Health and education platforms were promoted in order to improve community awareness on the social determinants of HT. ${ }^{18,19,20,21,22,23,24,25,26}$ In all of the studies, the interventions were tailored to be culturally and linguistically appropriate. ${ }^{18,19,20,21,22,23,24,25,26}$

\section{Outcomes}

\section{System and capacity changes}

The studies reported detailed quantitative clinical outcomes from the intervention. ${ }^{18,21,24}$ In the 'reach-out' study, the median age of participants was 58 years and 79\% were women. ${ }^{18} \mathrm{~A}$ total of 495 church members were screened and 94 participants enrolled in the study. Stroke and heart attack were the most common consequences of HT (32\% each) among intervention participants. ${ }^{18}$ In terms of BP control, the within group systolic BP change was -11.3 (standard deviation [SD] 22.9) $\mathrm{mmHg}$ and within control group was $-14.4(\mathrm{SD}=26.4) \mathrm{mmHg}$. In the quasi-experimental study, 99 participants attended screening: $47 \%$ were female, $82 \%$ had access to healthcare providers, $22 \%$ reported medication changes and $3.2 \%$ had attended chronic disease management (CDM) programmes. Total cholesterol (TC) and TC/high density lipoprotein (HDL) ratios reduced and HDL increased significantly. Thirty six percent had elevated BP, $58 \%$ had elevated TC/HDL ratios and $76 \%$ had a high risk of CVDs. On follow-up there was a decrease in TC/HDL ratios. ${ }^{21}$ The third study on community-based lifestyle intervention reported that at the 12-month follow-up in the intervention group, there was a significant reduction in systolic BP $(-4.9 \mathrm{mmHg}$ vs $2.4 \mathrm{mmHg}$ mean difference [MD] $7.3 \mathrm{mmHg} ; p<0.001)$, diastolic $\mathrm{BP}(-1.9 \mathrm{mmHg}$ vs $1.9 \mathrm{mmHg}$ MD $-3.8 \mathrm{mmHg} ; p<0.001)$ and fasting blood glucose $(-0.59 \mathrm{mmol} / \mathrm{L}$ vs $0.08 \mathrm{mmol} / \mathrm{L}$; $\mathrm{MD} 0.67 \mathrm{mmol} / \mathrm{L}$; $p<0.001)$. These differences were sustained at the 24 -month follow-up and the intervention group reported a sustainable decrease in self-reported intake of salt and cooking oil at the follow-up period. ${ }^{24}$

There was successful coalition formation with defined goals and objectives that culminated in a shared vision in all the studies. $18,19,20,21,22,23,24,25,26$ The health promotion and health education was carried out to improve community awareness on social determinants of HT in all the studies. $18,19,20,21,22,23,24,25,26$ Resuming traditions and customs, including culturally tailored interventions, was specifically mentioned in four studies. ${ }^{21,23,25,26}$ An effective and sustainable intervention to control HT in the elderly was achieved by the appropriation of agricultural resources, encouraging dance as a form of exercise, the use of motivational strategies, supporting institutions that work with the elderly and empowering facilitators..$^{23}$ Social and cultural contexts on food, body size and environmental factors had an influence on the prevention and control of HT in this community. For example, a large female body size was regarded as desirable in this community. ${ }^{25}$ Another study reportedly demonstrated the feasibility and value of implementing lay volunteer-led, culturally adapted sustainable opportunistic CVD risk factor screening in places of worship among minority ethnic groups. 
Where places of worship play a cultural and social role in many communities, studies suggest that they are feasible areas to identify individuals with CVD risk. ${ }^{21}$

Where lifestyles were improved to be more healthy, including reinforcing physical activity and reducing salt in the diet, healthy eating was reported. ${ }^{19,20,24,25,26}$ Significant improvements in medicine compliance, cutting down on salt and a reduction in alcohol use were reported among self-reported hypertensive Hispanics in REACH communities. $^{20}$ Also notable were improvements in clinical management, knowledge, beliefs and cultural competencies. ${ }^{20}$ Another study reported that the results indicated that comprehensive lifestyle interventions can be implemented effectively using a community-based approach, thus achieving long-term improvements in BP and glucose in the middle-aged and older population. ${ }^{24}$ Adapting the DASH diet to community settings through culturally appropriate, community-based efforts improved dietary behaviours, body mass index (BMI) and BP. ${ }^{19}$ The participants reported that as a result of access to MOTMGC nutrition gardens, they were more likely to eat fruit and vegetables, locally produced fresh foods and less processed fast foods. Those with a high participation in MOTMGC had favourable and healthy diets compared to those who did not participate. ${ }^{15}$

Capacity building and the empowerment of the community through coalitions took place, leading to the acceptability and sustainability of the interventions in all of the studies. ${ }^{18,19,20,21,22,23,24,25,26}$ Capacity building in the form of community control in agenda-setting and decision-making was developed among all the communities that were studied. There was improved engagement with the community, an enhanced understanding of problems, a strengthening of the leadership, and the creation and maintenance of networks. The SDH framework offered the opportunity to connect socioeconomic concerns to the increased risk of HT and other adverse health outcomes, providing an opportunity to engage multiple stakeholders in planning for the promotion of health and equity. ${ }^{18}$ The interventions were appropriate and sustainable in the communities. ${ }^{18,19,20,21,22,23,24,25,26}$ Community buy-in, ownership and the strong commitment of lay community members led to the dissemination of programmes beyond their original settings. ${ }^{18,19,20,21,22,23,24,25,26}$ The CHWs were empowered with diagnostic and management competencies on HT care, and the community developed trust in CHWs and the clinic system. ${ }^{26}$ Five of the studies ${ }^{20,22,23,25,26}$ reported that the study findings were disseminated and utilised, including influencing key policymakers for health. All studies $(n=9)$ reported that there was evidence-based data that were generated to inform policy formulation.

\section{Improved health}

The projects were successful due to active participation, skills development and the empowerment of communities. ${ }^{18,19,20,21,22,23,24,25,26}$ In one study, there was the establishment of community monitoring mechanisms and linked community health-based care to primary healthcare to enable the sustainability of service delivery. ${ }^{25}$ The participation of community organisations such as local FBOs $^{18}$ improved community awareness, as well as the implementation and dissemination of findings. Chronic disease management programmes were more accessible and this greatly improved health through educational programmes implemented in the community. ${ }^{21}$

Significant increases were reported in vegetable intake and compliance to medicines at follow-up, where participants in the intervention increased their activity levels one to two-fold during the follow-up period. ${ }^{24}$ This approach of lifestyle interventions conducted through primary care services may be a potential solution to combating HT in resource-limited settings. ${ }^{24}$ There was a documented decline in the prevalence of HT, obesity and overweight respondents in the intervention, but not the comparison county. ${ }^{19}$ All individuals who received intervention sustained behavioural changes. ${ }^{18,19,20,21,22,23,24,25,26}$

\section{Discussion}

The findings from this scoping study confirmed that the use of CBPR in the prevention and control of HT was still an emerging field, as evidenced by the small number of studies that were found in the literature. The majority of the studies were published after the year 2010, with only one having been published prior to 2010 .

Regardless of the context setting - whether rural or urban - the studies were conducted in disadvantaged communities where there was poverty, a lack of social cohesion and marginalisation. These communities included displaced, elderly hypertensive citizens, African Americans, South Asian Canadians and Hispanics. All of these groups were racial or ethnic minorities that experienced health disparities and lacked social justice. In all of the studies, $18,19,20,21,22,23,24,25,26$ the context of the study related to a high prevalence of HT. Socio-economic and environmental factors influenced the $\mathrm{SDH}$. In all of the studies, the importance of HT as a key contributor to CVDs was emphasised.

The common finding was that for all of the studies, ${ }^{18,19,20,21,22,23,24,25,26}$ the context was that the communities were marginalised, had a high prevalence of HT and poor SDH. A CBPR approach (1) took into consideration contextspecific challenges in marginalised communities, ${ }^{18,19,20,21,22,23,24,25,26}$ (2) aimed to provide culturally appropriate and logistically sound research by shaping the scope of the research, interpretation and dissemination of findings, $18,19,20,22,23,24,25,26$ (3) generated capacity to recruit community members to advisory boards and implementation by community members, ${ }^{19,21,22,23,26}$ (4) offered capacity for partnerships by researchers and the community $18,19,20,21,22,23,24,25,26$ and (5) offered long-term capacity to sustain the project goals beyond funded timelines. ${ }^{18,19,21,23,24,25,26}$ 
All of the reviewed articles described the formation of coalitions that included the community and the researchers. This offers the benefit of sharing ideas, including indigenous knowledge, while the academics could understand the social determinants of health from the community members themselves. Other community partners were also roped in to identify and address complex health problems. Moreover, the inequities were dealt with utilising multiple stakeholder participation. This process created a skills transfer within the community that participated in the project. There was community acceptance and ownership of the project, leading to its sustainability beyond project timelines. Even though differences were noted in the implementation of CBPR partnerships, the overarching principles of coalition formation were adhered to, including power that was shared equally, and active participation in all of the stages of the projects (as well as the dissemination of the results). Various methods were utilised for CBPR implementation and there was no standardisation of methods used, as seen with the use of qualitative mixed methods, quasi-experimental and RCTs in the studies.

The intervention had three major approaches: to build strong community-based coalitions; to focus on policy, systems and environment (PSE) changes; and the cultural and linguistic tailoring of interventions. All of the interventions which focused on minority groups had tailored interventions that targeted specific barriers that had been shown to be effective in reducing health disparities.

All of the studies had the primary objective of influencing human behaviour. Health behaviour modification theories were used to model CBPR to influence human behaviour. To achieve this change while implementing CBPR, various health education platforms were created and reported in all of the studies. Changes reported in HT outputs were as a result of a change in behaviour. To ensure behaviour change, community participation was encouraged through partnerships or the formation of coalitions. The application of CBPR principles of equitable power distribution and community participation with a shared vision contributed to favourable HT outcomes in the community. During project implementation, the community helped to shape the scope of the research, data collection, and interpretation and dissemination of findings. Socio-cultural contexts, traditions and hobbies of the community members affected by HT were taken into consideration when designing programmes for management that complement pharmacological therapy.

Partnerships or coalitions were used consistently across all CBPR implementation studies that were reviewed. The formation of coalitions was guided by well-defined goals and objectives where the inclusive team shared a common vision. ${ }^{27}$ Synergies built on success enhanced future successes in the community management of HT. The aim of the partnerships was to build capacity among inhabitants of disadvantaged communities living with a high prevalence of HT. In forming these partnerships, engagement occurred on equal terms between academics and community members. The ultimate aim of these coalitions was capacity building, which led to the empowerment of the community. Active participation brought about context-specific problem identification and measured task-shifting, and encouraged task-sharing and knowledge transfer which influenced behaviour modification or behaviour change. ${ }^{27}$ In addition, there was participant satisfaction and intervention sustainability in the community. This guaranteed improved community knowledge in the monitoring and control of HT.

The implementation of CBPR in turn improved clinical practice while addressing issues that were important to the community. Traditional types of research discouraged community experts from sharing invaluable expertise on perspectives and ideas as it did not foster community engagement and involvement. ${ }^{28}$ It has been noted that a few successful interventions often disappeared with the cessation of donor funding; therefore, CBPR offers a new approach which guarantees sustainable social change. ${ }^{27}$ The benefits of CBPR include capacity building and empowerment, and guarantees the sustainability of the intervention in the community post project funding timelines.

Healthy lifestyle improvement included reinforcing physical activity and reducing salt in the diet, and healthy eating was reported. ${ }^{19,20,24,25,26}$ Significant improvements in medicine compliance, cutting down on salt and the reduction in alcohol use was reported among self-reported hypertensive Hispanics in REACH communities. ${ }^{20}$ In another study, the primary prevention of HT was enhanced by encouraging a healthy diet such as the consumption of fruit and vegetables, locally produced fresh foods and less processed fast foods. ${ }^{19}$ This approach of lifestyle interventions conducted through primary care services may be a potential solution to combating HT in resource-limited settings. ${ }^{24}$ The projects were successful as a result of active participation, skills development and the empowerment of communities. 18,19,20,21,22,23,24,25,26 All individuals who received intervention sustained behavioural changes. ${ }^{18,19,20,21,22,23,24,25,26}$ The delivery of lifestyle interventions by community health staff is a promising vehicle for the primary prevention of CVD..$^{24}$ Ultimately, the implementation of CBPR improved health.

Despite a large body of research on HT documenting socio-economic disparities, access to health and quality of healthcare, appropriate interventions to improve health have lagged behind. ${ }^{11,29}$ By implementing CBPR, locally feasible, acceptable and sustainable strategies can be developed to address these key social determinants to health. A systematic review of randomised control trials to determine interventions used to control BP in patients conducted by Glynn et al. (2010) concluded that education alone, either to health professionals or patients, was not associated with a large net reduction in BP. ${ }^{30}$ There is a knowledge gap in the literature on the impact of CBPR on HT outcomes, and the available studies on the use of CBPR 
in cardiovascular medicine primarily focus on the prevention and control of HT. There were also challenges in determining the extent to which the effect of CBPR was noted in health disparities post intervention. This was because there is no scientific methodology to prove the actual impact of CBPR, as the method only infers the favourable outputs to the intervention.

The variations in methodologies to implement the CBPR intervention may have led to non-standardisation, hence the challenges that were reported in the studies. Similarly, there were no substantive data to back up the long-term impact of reducing HT that could be proved using CBPR methodologies. ${ }^{22}$ Some of the studies relied on the self-reporting of patients and this could have introduced bias into those studies. ${ }^{20,22}$ It was notable that economic constraints and cultural beliefs and practices influenced a community's food choices and participation in physical activities. ${ }^{25}$ This became a challenge as these factors determined the primary prevention of CVDs. Despite considerable effectiveness, the delivery of such intensive lifestyle interventions to effectively contribute to behavioural change required the involvement of community organisations, expertise, capacity development and resources. ${ }^{24}$

\section{Conclusion and implications for further research}

A CBPR framework can be used to define the context, group dynamics, implementation and outcomes of HT by using theories of human behaviour. The formation of academiccommunity coalitions help to address complex health problems and inequities utilising multiple stakeholder participation. The coalitions in CBPR aim to encourage community control in decision-making and ensure active participation throughout the project phases, including the dissemination of findings. Equitable power-sharing and engagement between the academic-community partnerships is promoted.

It is possible to apply the principles of CBPR in the primary and secondary prevention even though different methodologies can be used in the process. The aim of implementing CBPR is to change a particular behaviour in a community and to also address health inequities and disparities among minority groups in society. To achieve this, health education platforms specifically adapted for the language, culture and literacy needs of the minority groups should be implemented. In so doing, there should be a deliberate effort to build capacity and empower minorities. For primary and secondary prevention to be a success, an improvement to a healthy lifestyle needed to include reinforcing physical activity and reducing salt in the diet. Healthy eating could indeed be achieved through CBPR on HT. When properly implemented, CBPR will lead to the acceptability and sustainability of HT management and intervention strategies. The study findings from CBPR can be utilised to influence key policy changes for health planners.

\section{Acknowledgements Competing interests}

The authors declare that they have no financial or personal relationships that may have inappropriately influenced them in writing this article.

\section{Authors' contributions}

P.T.C. (University of KwaZulu-Natal) was responsible for searching the databases and obtaining articles, which were critically appraised by both authors. P.T.C. wrote the initial manuscript and M.N. (University of KwaZulu-Natal) reviewed and edited the manuscript.

\section{Funding information}

This research received no specific grant from any funding agency in the public, commercial or not-for-profit sectors.

\section{Data availability statement}

Data sharing is not applicable to this article as no new data were created or analysed in this study.

\section{Disclaimer}

The views and opinions expressed in this article are those of the authors and do not necessarily reflect the official policy or position of any affiliated agency of the authors.

\section{References}

1. World Health Organization (WHO). Noncommunicable diseases and their risk factor [homepage on the Internet]. [cited 2018 Dec 08]. Available from: www. who.int/ncd_surveillance/en/

2. Kearney PM, Whelton M, Reynolds K, Whelton PK, He J. Worldwide prevalence of hypertension: A systematic review. J Hypertens. 2004;22(1):11-19. https://doi. org/10.1097/00004872-200401000-00003

3. World Health Organization. A global brief on hypertension: Silent killer, global public health crisis World Health Day. 2013. Report, 1-39. Geneva, Switzerland: World Health Organization.

4. World Health Organization. Preventing chronic diseases: A vital investment [homepage on the Internet]. c2005 [cited 2018 Dec 08]. Available from: http:// whqlibdoc.who.int/publications/2005/9241563001_eng.pdf

5. Beaglehole R, Epping-Jordan J, Patel V, et al. Improving the prevention and management of chronic disease in low-income and middle-income countries: A priority for primary health care. Lancet. 2008;372(9642):940-949. https://doi. org/10.1016/S0140-6736(08)61404-X

6. Hills M, Mullett J, Carroll S. Community-based participatory action research: Transforming multidisciplinary practice in primary health care. Rev Panam Salud Pública. 2007:21(2/3):125-135. https://doi.org/10.1590/S102049892007000200007

7. Zenz A. Evaluating empowerment: The world vision area development programme [homepage on the Internet]. Washington, DC: World Bank; 2006 [cited 2018 Nov 19]. Available from: http://www.devnet.org.nz/conf/Papers/zenz.pdf

8. Rahman MA, Fals-Borda O. A self-review of PAR. In: Action and knowledge: Breaking the monopoly with participatory action research. London: Intermediate Technology Publications; 1991

9. Israel BA, Schulz AJ, Parker EA, Becker AB. Review of community-based research: Assessing partnership approaches to improve public health. Annu Rev Public Health. 1998;19(1):173-202. https://doi.org/10.1146/annurev. publhealth.19.1.173

10. Schulz AJ, Parker EA, Israel BA, Allen A, Decarlo M, Lockett M. Addressing social determinants of health through community-based participatory research: The East Side Village Health Worker Partnership. Health Educ Behav. 2002;29(3):326-341. https://doi.org/10.1177/109019810202900305

11. Wallerstein N, Duran B. Community-based participatory research contributions to intervention research: The intersection of science and practice to improve health equity. Am J Public Health. 2010;100(Suppl 1):S40-S46. https://dx.doi. org/10.2105\%2FAJPH.2009.184036 
12. Lazarus S, Duran B, Caldwell L, Bulbulia S. Public health research and action: Reflections on challenges and possibilities of community-based participatory research. London: Intech Open Access Publisher; 2012.

13. Wallerstein N, Duran B. The theoretical, historical, and practice roots of CBPR. In: Minkler $\mathrm{M}$, Wallerstein $\mathrm{N}$, editors. Community-based participatory research for health. 2nd ed. San Francisco, CA: John Wiley and Sons.

14. Davis K, Drey N, Gould D. What are scoping studies? A review of the nursing literature. Int J Nurs Stud. 2009;46(10):1386-1400. https://doi.org/10.1016/j. ijnurstu.2009.02.010

15. Levac D, Colquhoun H, O'Brien KK. 2010. Scoping studies: Advancing the methodology. Implement Sci. 2010;5(1):69. https://doi.org/10.1186/1748-5908-5-69

16. Munn Z, Peters MDJ, Stern C, Tufanaru C, McArthur A, Aromataris E. Systematic review or scoping review? Guidance for authors when choosing between systematic or scoping review approach. BMC Med Res Methodol. 2018;18:143. https://doi.org/10.1186/s12874-018-0611-x

17. Arksey H, O'Malley L. Scoping studies: Towards a methodological framework. Int J Soc Res Methodol. 2005;8(1):19-32. https://doi.org/10.1080/ 1364557032000119616

18. Skolarus LE, Cowdery J, Dome M, et al. Reach out churches: A community-based participatory research pilot trial to assess the feasibility of a mobile health technology intervention to reduce blood pressure among African Americans. Health Promot Pract. 2018:19(4):495-505. https://doi.org/10.1177/152483 9917710893

19. Baker EA, Barnidge EK, Schootman M, Sawicki M, Motton-Kershaw FL. Adaptation of a modified DASH diet to a rural African American community setting. Am J Prev Med. 2016;51(6):967-974. https://doi.org/10.1016/j.amepre.2016.07.014

20. Liao Y, Siegel PZ, White S, Dulin R, Taylor A. Improving actions to control high blood pressure in Hispanic communities - Racial and ethnic approaches to community health across the U.S. Project, 2009-2012. Prevent Med. 2016;83:11-15. https:// doi.org/10.1016/j.ypmed.2015.11.027

21. Jones CA, Nanji A, Mawani S, et al. Feasibility of community-based screening for cardiovascular disease risk in an ethnic community: The South Asian Cardiovascular Health Assessment and Management Program (SA-CHAMP). BMC Public Health 2013;13:160. https://doi.org/10.1186/1471-2458-13-160
22. Lucumí DI, Schulz AJ, Torres-Gil JE, Gonzales L, Ramírez K. Establishing a local coalition for addressing social determinants of hypertension in Quibdó (Colombia): A description and reflection on the process. Glob Health Promot. 2018;27(1):2020. A description and reflection on the process. Glob
https://doi.org/10.1177/1757975918774784

23. López-Mateus MC, Hernández-Rincón EH, Correal-Muñoz CA, Cadena-Buitrago GP, Galvis-Díaz IJ, Romero-Prieto GE. An educational strategy that promotes healthy habits in elderly people with hypertension in a municipality of Colombia: healthy habits in elderly people with hypertension in a municipality of Colombia: org/10.5867/medwave.2017.08.7072

24. Lin A, Zhang G, Liu Z, Gu J, Chen W, Luo F. Community-based lifestyle intervention for reducing blood pressure and glucose among middle-aged and older adults in China: A pilot study. Int J Environ Res Public Health. 2014;11(11):11645-11663. https://doi.org/10.3390/ijerph111111645

25. Bradley HA, Puoane T. Prevention of hypertension and diabetes in an urban setting in South Africa: Participatory action research with community health workers. Ethn Dis. 2007;17(1):49-54.

26. Chimberengwa PT, Naidoo M. A description of community-based participatory research of hypertension awareness, prevention and treatment in a district of Matabeleland South Province, Zimbabwe. Afr J Prm Health Care Fam Med. 2019;11(1):a1839. http://dx.doi.org/10.4102/phcfm.v11i1.1839

27. Mash B. African primary care research: Participatory action research. Afr J Prm Health Care Fam Med. 2014;6(1):a585. https://doi.org/10.4102/phcfm. v6i1. 585

28. Green LW, Mercer SL. Can public health researchers and agencies reconcile the push from funding bodies and the pull from communities? Am J Public Health 2001;91(12):1926-1929. https://doi.org/10.2105/AJPH.91.12.1926

29. Agency for Healthcare Research and Quality. 2006 National Healthcare Disparities Report. Washington, DC: US Department of Health and Human Services; 2006. AHRQ No. 05-0014.

30. Glynn LG, Murphy AW, Smith SM, Schroeder K, Fahey T. Interventions used to improve control of blood pressure in patients with hypertension. Cochrane Database Syst Rev. 2010;3:CD005182. https://doi.org/10.1002/14651858. CD005182.pub4 